\title{
PENERAPAN METODE DMAIC DALAM PENINGKATAN ACCEPTANCE RATE UNTUK UKURAN PANJANG PRODUK BUSHING
}

\author{
Ferdian Hartoyo; Yudha Yudhistira; Andry Chandra; Ho Hwi Chie \\ Computerized Accounting Department, School of Information Systems, Binus University \\ Jl. K.H. Syahdan No. 9, Palmerah, Jakarta Barat 11480
}

\begin{abstract}
Bushing is one of the eminent product of PT Indokarlo Mighty. The company requires some suppliers of iron cutting services to continue providing high qualified raw materials. The quality is the accuracy of the intended length of the products which is able to meet the requirements of the requested length. The purpose of this study is to determine what factors caused the defect on the length of the products. In addition, it is objected to provide appropriate solutions to eliminate to the factors, so that the number of defected products can be reduced. This study uses the methodology of Six Sigma improvement models Define-Measure-Analyze-ImproveControl (DMAIC) to make improvements in the quality of services provided by PT Argatama Multi Agung, while the improvement phase uses Design of Experiment (DOE) to find the machine configuration that can produce the best quality products. A significant increase in sigma is obtained from the conducted research.
\end{abstract}

Keywords: bushing, length measurement, DMAIC, Design of Experiment

\begin{abstract}
ABSTRAK
Bushing merupakan salah satu produk unggulan PT Indokarlo Perkasa. Perusahaan ini membutuhkan beberapa supplier penyedia jasa pemotongan besi untuk dapat terus menyediakan bahan baku yang berkualitas. Kualitas yang dimaksudkan adalah keakuratan ukuran panjang produk yang dihasilkan memenuhi persyaratan ukuran panjang produk yang diminta. Tujuan dari penelitian ini adalah mengetahui faktor apa saja yang menyebabkan terjadinya kecacatan panjang pada produk yang dimaksud. Dan juga untuk memberikan solusi yang tepat agar faktor yang menyebabkan terjadinya kecacatan ini dapat dihilangkan sehingga jumlah produk cacat yang dihasilkan juga berkurang. Penelitian ini menggunakan metodologi Six Sigma dengan model perbaikan Define-Measure-Analyze-Improve-Control (DMAIC) untuk melakukan perbaikan pada kualitas jasa yang disediakan oleh PT Argatama Multi Agung. Tahap improvement menggunakan metode Design of Experiment (DOE) untuk mencari konfigurasi mesin yang dapat menghasilkan kualitas terbaik. Dari penelitian yang dilakukan didapat kenaikan sigma yang cukup signifikan.
\end{abstract}

Kata kunci: bushing, ukuran panjang, DMAIC, Design of Experiment 


\section{PENDAHULUAN}

Saat ini dunia perindustrian semakin kompetitif, sehingga pelaku bisnis dituntut untuk memiliki keunggulan yang tidak dimiliki pesaing lainnya. Salah satu keunggulan yang dapat dimiliki suatu perusahaan adalah kualitas yang lebih baik dibanding dengan perusahaan lain yang bergerak di bidang yang sama. Selain dapat memberikan keunggulan dalam hal persaingan dengan perusahaan lain, kualitas juga dapat meningkatkan keuntungan perusahaan itu sendiri secara langsung dengan penurunan biaya produksi dan penurunan kerugian yang diakibatkan oleh barang cacat.

PT Indokarlo Perkasa (IKP) adalah perusahaan yang bergerak di bidang manufaktur yang memproduksi sparepart otomotif. Untuk mendukung proses produksi yang panjang pada PT IKP diperlukan banyak supplier. Khusus untuk jasa pemotongan besi berbagai macam ukuran PT IKP melakukan order ke PT Argatama Multi Agung (AMA) untuk hampir 95\% pekerjaan pemotongan. PT IKP memilih PT AMA sebagai mitra dikarenakan tariff jasa yang cukup murah, akan tetapi saat ini ada isu kualitas dimana hasil pemotongan ada yang tidak memuaskan. Atas kondisi ini, maka penelitian yang dilakukan di PT IKP membahas mengenai peningkatna kualitas hasil jasa yang diberikan oleh PT AMA bagi PT IKP.

Dapat dirumuskan permasalahan yang menjadi bahasan penelitian ini, yaitu: (1) penentuan jenis cacat apa yang paling banyak terjadi; (2) penentuan kapabilitas proses produksi saat ini dibandingkan dengan kritera ukuran yang ditetapkan; (3) identifikasi faktor penyebab cacat yang timbul; (4) perumusan usulan solusi apa yang terbaik untuk mengurangi terjadinya cacat panjang; (5) estimasi besar keuntungan yang akan didapatkan dari penerapan solusi yang disarankan.

Agar penelitian yang dilakukan lebih terarah dan terfokus kepada inti permasalahan serta mengingat keterbatasan waktu yang ada, dalam penelitian ini diperlukan suatu pembatasan ruang lingkung, yaitu: (1) penelitian dilakukan di salah satu supplier PT Indokarlo Perkasa yang bermasalah, yaitu PT Argatama Multi Agung; (2) jenis cacat yang akan diteliti adalah jenis cacat ukuran panjang.

Adapun adanya tujuan dan manfaat dari penelitian ini adalah: (1) mengetahui cacat apa yang paling banyak terjadi; (2) mengetahui seberapa besar kapabilitas proses produksi yang ada saat ini untuk mememuhi kriteria ukuran barang yang diminta oleh konsumen; (3) mengetahui faktor apa saja yang menyebabkan terjadinya defect (cacat) panjang; (4) mengetahui solusi yang terbaik untuk mengurangi terjadinya defect panjang; (5) mengetahui seberapa besar keuntungan yang akan didapatkan dari penerapan solusi yang disarankan.

\section{METODE}

Metodologi penelitian yang digunakan adalah Six Sigma, yang dimulai dari tahapan defineatau penentuan permasalahan yang akan dijadikan landasan perbaikan, selanjutnya measure yaitu melakukan pengukuran yang diperlukan sebagai landasan usulan perbaikan yang akan dijalankan, analyze atau melakukan analisis atas hasil pengukuran dan merumuskan langkah-langkah perbaikan yang perlu dilakukandan control atau tindakan pengawasan atas pelaksanaan perbaikan yang dilakukan.

Six Sigma berasal dari serangkaian praktek yang dirancang untuk memperbaiki proses manufaktur dan menghilangkan cacat, namun penerapannya kemudian meluas ke jenis proses usaha yang lain. Dalam Six Sigma, cacat didefinisikan sebagai output/keluaran proses apapun yang tidak 
memenuhi spesifikasi pelanggan atau yang bisa mengarah pada hasil keluaran yang tidak memenuhi spesifikasi pelanggan (Mehrjerdi, 2011).

Six Sigma sangat terinspirasi oleh enam dekade sebelumnya dari metodologi peningkatan kualitas seperti kendali mutu, TQM, dan cacat nol (zero defect), berdasarkan kerja pionir seperti Shewhart, Deming, Juran, Ishikawa, Taguchi dan lain-lain.

Seperti pendahulunya, doktrin Six Sigma menegaskan bahwa: (1) upaya terus menerus untuk mencapai hasil proses stabil dan bisa diprediksi (yaitu, mengurangi variasi proses) adalah sangat penting untuk kesuksesan bisnis; (2) manufaktur dan proses bisnis memiliki karakteristik yang dapat diukur, dianalisis, diperbaiki dan dikendalikan; (3) peningkatan kualitas berkelanjutan membutuhkan komitmen dari seluruh organisasi, terutama dari manajemen tingkat atas.

Six Sigma adalah merek layanan dan merek dagang terdaftar dari Motorola Inc pada tahun 2006. Motorola melaporkan bahwa lebih dari US \$ 17 miliar dalam simpanan dari Six Sigma. Pengadopsi awal Six Sigma lain yang mencapai sukses dan dipublikasikan adalah Honeywell (sebelumnya dikenal sebagai AlliedSignal) dan General Electric, di mana Jack Welch memperkenalkan metode tersebut. Pada akhir tahun 1990-an, sekitar dua-pertiga dari 500 organisasi Fortune telah mulai mengawali Six Sigma dengan tujuan untuk mengurangi biaya dan meningkatkan kualitas. Dalam beberapa tahun terakhir, beberapa praktisi telah menggabungkan Six Sigma dengan ide-ide lean manufacturing untuk menghasilkan metodologi bernama Lean Six Sigma.

Metode yang digunakan dalam penelitian Six Sigma ini adalah metode DMAIC, yang merupakan singkatan dari define, measure, analyze, improve dan control. Metode ini digunakan untuk memperbaiki permasalahan yang muncul dalam segi bisnis. DMAIC adalah salah satu prosedur pemecahan masalah yang dipakai secara luas dalam masalah peningkatan kualitas dan perbaikan proses (Desai \& Shrivastava, 2008; Evans \& Lindsay 2007). DMAIC selalu diasosiasikan dengan aktivitas Six Sigma, dan hampir semua penerapan Six Sigma menggunakan pendekatan DMAIC.

\section{Define}

Tujuan dari langkah define pada pendekatan DMAIC adalah untuk mengidentifikasi tahap untuk menentukan pokok permasalahan, tujuan penelitian, dan lingkup pada proses. Untuk itu diperlukan adanya data kebutuhan pelanggan sehingga dapat diketahui pokok permasalahan yang harus diteliti, kemudian akan dilakukan aktivitas beserta deskripsi dalam suatu proses yang terkait dengan proses, serta inspeksi suatu produk sehingga langkah berikutnya yang dilakukan adalah menentukan apa yang menjadi Critical to Quality (CTQ) bagi pelanggan.

\section{Project Charter}

Fase ini merupakan penentuan tujuan dan ruang lingkup proyek, mengumpulkan informasi tentang proses dan pelanggan, dan menentukan kiriman kepada pelanggan (internal dan external). Beberapa elemen yang termasuk dalam project charter adalah sebagai berikut (Desai \& Shrivastava, 2008): (1) problems statements, yaitu deskripsi singkat dari masalah yang perlu ditangani. Sebuah pernyataan masalah yang baik harus menjawab pertanyaan-pertanyaan seperti apa masalahnya, siapa yang memiliki masalah (customer) dan apa saja ruang lingkup yang diperlukan; (2) project goals, yaitu proyek atau penelitian terhadap suatu masalah harus memiliki tujuan yang jelas yang langsung terkait terhadap solusi dari permasalahan tersebut; (3) project scope, yaitu memahami persyaratan dari proyek Six Sigma DMAIC sangat penting terhadap lingkup project. Tanpa pemahaman ini, sangat sulit untuk memberikan keterangan dari sebuah proyek untuk memperoleh tujuan yang jelas, singkat dengan batas-batas yang akan memungkinkan resolusi masalah tepat waktu. 


\section{Penentuan CTQ (Critical to Quality)}

CTQ adalah atribut-atribut yang sangat penting untuk diperhatikan karena berkaitan langsung dengan kebutuhan dan kepuasan pelanggan. CTQ merupakan elemen dari suatu produk, proses, atau spesifikasi lain yang berhubungan langsung kepada kepuasan pelanggan. Sebelum melakukan pengukuran terhadap CTQ, perlu dilakukan evaluasi terhadap sistem pengukuran yang ada agar menjamin efektivitas sepanjang waktu (Gaspersz, 2002).

\section{SIPOC Diagram}

Identifikasi langkah-langkah aktivitas beserta deskripsinya dalam suatu proses yang terkait dapat pula menggunakan proses flowchart, yang menjelaskan proses suatu produk serta inspeksi yang dilakukan dan alat yang berguna dan paling banyak digunakan dalam manajemen dan peningkatan proses adalah SIPOC, yaitu: suppliers, inputs, processes, output, customers.

\section{Measure}

Tahap measure merupakan langkah operasional dalam program peningkatan kualitas Six Sigma. Terdapat tiga hal pokok yang harus dilakukan dalam tahap ini, yaitu: (1) memilih dan menentukan karakteristik kualitas (CTQ) kunci yang berhubungan langsung dengan kebutuhan spesifik customers, (2) mengembangkan suatu rencana pengumpulan data melalui pengukuran yang dapat dilakukan pada tingkat proses, input, dan output, dan (3) mengukur kinerja pada tingkat proses, input dan output (Gaspersz, 2002).

Pengukuran pada tingkat output dilakukan untuk mengetahui sejauh mana output dari suatu proses dalam memenuhi kebutuhan customers. Hasil pengukuran pada tingkat output dapat berupa data variabel dan data atribut, yang akan ditentukan kinerjanya berdasarkan pengukuran sebagai berikut.

\section{DPMO (Defect Per Million Opportunities)}

DPMO adalah ukuran kegagalan dalam program peningkatan kualitas Six Sigma, yang menunjukkan kegagalan per sejuta kesempatan. Target dari pengendalian kualitas Six Sigma Motorola sebesar 3,4 DPMO tidak diintepretasikan sebagai 3,4 unit output yang cacat dari sejuta unit output, tetapi sebagai dalam satu unit produk tunggal terdapat rata-rata kesempatan untuk gagal dari suatu CTQ adalah 3,4 kegagalan per satu juta kesempatan.

\section{Process Capability}

Process Capability adalah kemampuan proses untuk memproduksi output sesuai dengan kebutuhan pelanggan (Gasperz, 2005). Indeks Cpm mengukur kapabilitas yang didefinisikan sebagai:

$$
C p m=\left(U S L-L S L / \sqrt{(\mu-T)^{2}+\sigma^{2}}\right.
$$

$$
\begin{array}{ll}
\text { dengan } & \text { keterangan: } \\
\text { USL } & =\text { upper spesification limit (batas spesifikasi atas) } \\
\text { LSL } & =\text { lower spesification limit (batas spesifikasi bawah) } \\
\mu & =\text { nilai rata-rata (mean) proses aktual } \\
\mathrm{T} & =\text { nilai target dari produk } \\
\sigma & =\text { nilai variance dari ukuran variansi proses analyze }
\end{array}
$$




\section{Analyze}

Tujuan tahap analyze adalah untuk menggunakan data atau informasi pada tahap pengukuran (measure) untuk memulai menentukan hubungan sebab akibat pada proses dan untuk memahami perbedaan dari variabilitas. Dengan kata lain, bahwa pada tahap ini, kita akan menentukan penyebab paling utama dari defect, masalah kualitas, masukan dari pelanggan, waktu siklus, dan lain-lain (Gaspersz, 2002). Tahap ini perlu melakukan beberapa hal berikut:

\section{Analisis terhadap Kapabilitas Proses}

Dalam menentukan apakah suatu proses berada dalam kondisi stabil, perlu membutuhkan alatalat atau metode statistika sebagai alat analisis. Kontribusi utama dari penggunaan metode statistika dalam pengendalian sistem industri adalah memisahkan variasi total dalam suatu proses, contohnya analisis kapabilitas proses yang memiliki batas spesifikasi dan analisis kapabilitas proses untuk data atribut.

\section{Identifikasikan Sumber dan Akar Penyebab Cacat}

Tools Six Sigma yang digunakan dalam tahap ini adalah: (1) Pareto Chart, yaitu quality improvement tool yang sering digunakan untuk mendefinisikan langkah-langkah pengukuran, yang merepresentasikan secara grafis tentang distribusi frekuensi dari masing-masing perfomance. Diagram Pareto ini merupakan suatu gambar yang mengurutkan klasifikasi data dari kiri ke kanan menurut urutan ranking tertinggi hingga terendah. Hal ini dapat membantu menemukan permasalahan yang terpenting untuk segera diselesaikan (ranking tertinggi) sampai dengan yang tidak harus segera diselesaikan (ranking terendah) (Dreachslin, 2007); (2) Fishbone Diagram, adalah metode yang menjelaskan akar-akar penyebab dari masalah yang mengkategorikan sumber-sumber penyebab berdasarkan prinsip 7M, yaitu man power, machines, methods, materials, media, motivation, money (Gaspersz, 2002).

\section{Improve}

Tahap inprove bertujuan untuk mengoptimasi solusi yang ditawarkan akan memenuhi atau melebihi tujuan perbaikan dari proyek. Selama fase improve, tim proyek merencanakan optimasi proses melalui design of experiment (Wijaya \& Kusuma, 2008).

Pada dasarnya, rencana-rencana tindakan akan mendeskripsikan tentang alokasi sumbersumber daya serta prioritas dan alternatif yang akan dilakukan dalam implementasi dari rencana itu. Bentuk pengawasan dan usaha-usaha untuk mempelajari melalui pengumpulan data dan analisis ketika implementasi dari suatu rencana juga harus direncanakan pada tahap ini (Gaspersz, 2002).

\section{Control}

Control adalah tahap operasional terakhir dalam proyek peningkatan kualitas Six Sigma. Pada tahap ini hasil-hasil peningkatan kualitas didokumentasikan, prosedur-prosedur yang baik didokumentasikan dan dijadikan pedoman kerja standar, serta kepemilikan atau tanggung jawab ditransfer kepada pemilik atau penanggung jawab proses (Donald, Suzanne, \& Elaine, 2003).

Standardisasi diperlukan sebagai tindakan pencegahan untuk memunculkan kembali masalah kualitas yang pernah ada. Pendokumentasian praktek-praktek kerja standar juga bermanfaat sebagai bahan dalam proses belajar yang terus-menerus, baik bagi karyawan baru maupun karyawan lama, serta menjadikan informasi yang berguna dalam mempelajari masalah-masalah kualitas di masa mendatang sehingga tindakan peningkatan yang efektif dapat dilakukan (Gaspersz, 2002). 
Pada tahap control, dilakukan integrasi yang bertujuan mengintegrasikan metode-metode standar dan proses ke dalam siklus desain, dimana salah satu prinsip dari design for Six Sigma adalah bahwa proses desain harus menggunakan komponen-komponen dan proses-proses yang ada. Integrasi juga penting untuk mengintegrasikan Six Sigma ke dalam praktek bisnis yang dikelola (Mehrjerdi, 2011).

\section{HASIL DAN PEMBAHASAN}

\section{Tahap Define}

Pada tahap ini akan dilakukanidentifikasi masalah. Agar identifikasi masalah, cakupan penelitian, anggota proyek, target pencapaian, serta targer waktu penyelesaian terlihat dengan jelas dan ada hitam di atas putih, maka dibuatlah Project Charter. Setelah project charter dibuat, langkah selanjutnya dari tahap define ini adalah membuat SIPOC (supplier, input, process, output, customer) diagram. Agar aliran barang dari tangan supplier sampai ke tangan customer dapat terlihat dengan jelas. Berikut adalah Project Charter (Gambar 1) serta SIPOC diagram (Gambar 2) dari tahap ini.

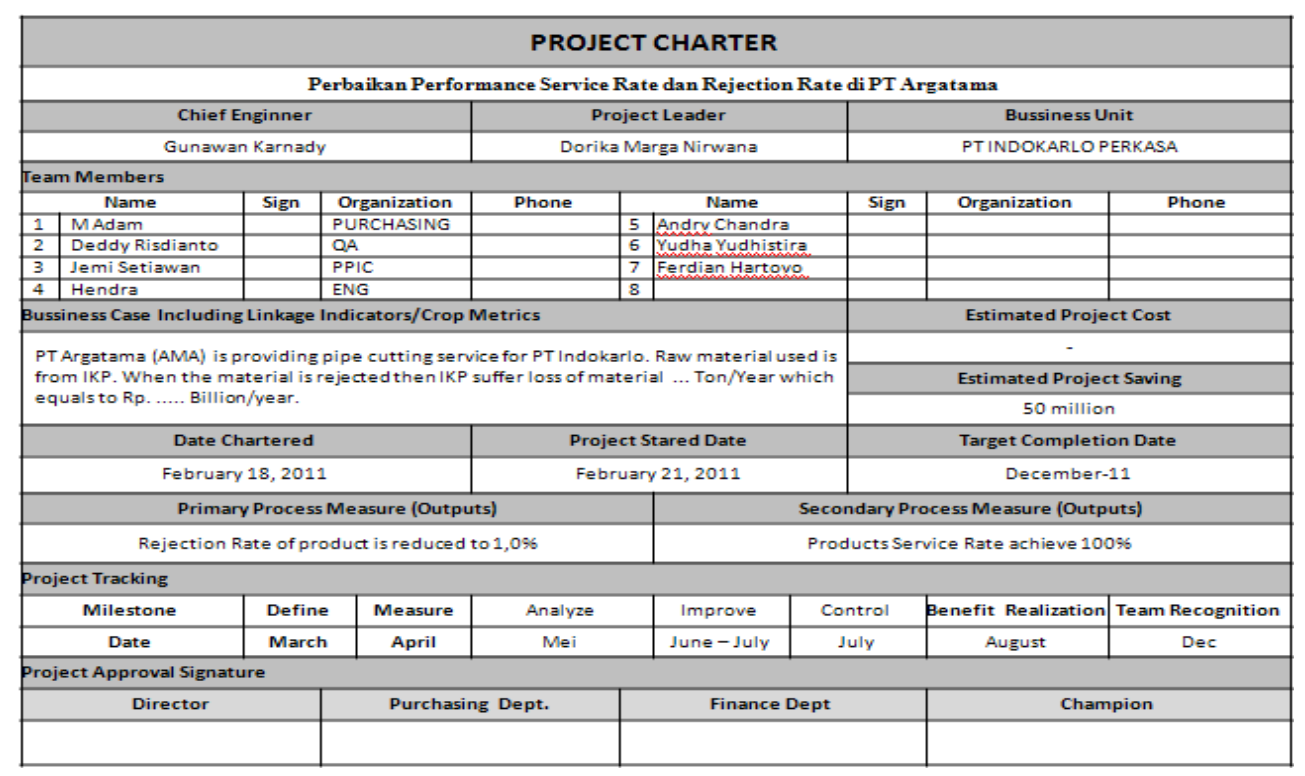

Gambar 1. Project Charter.

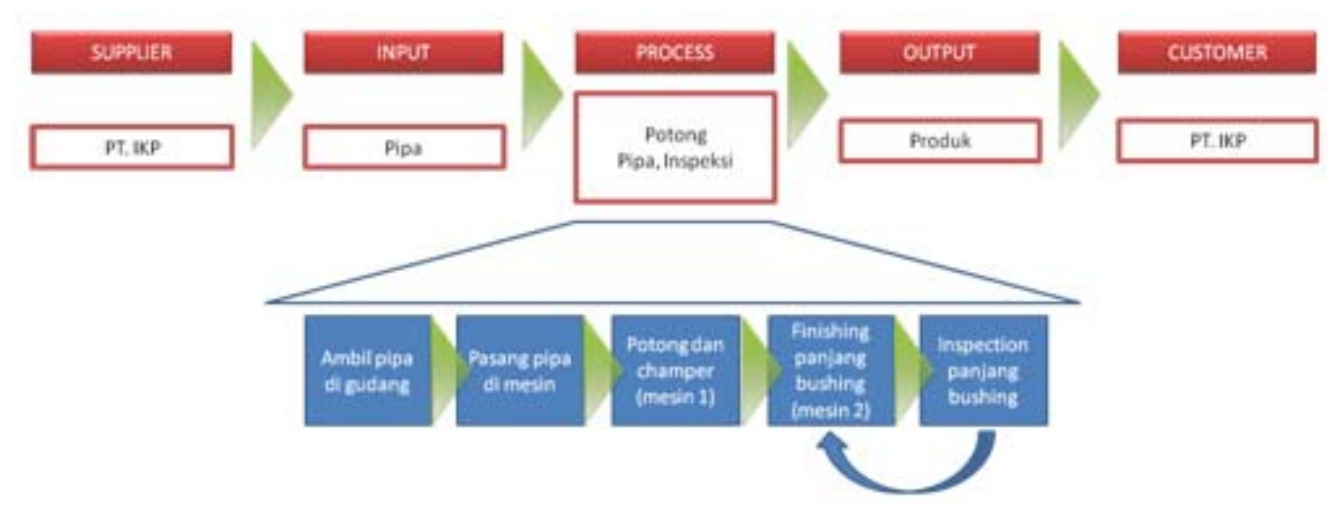

Gambar 2. SIPC Diagram. 
Jika dilihat dari diagram SIPOC diatas, PT Indokarlo Perkasa adalah konsumen. Dalam penelitian ini diketahui bahwa keinginan dari PT Indokarlo Perkasa sebagai konsumen adalah menurunkan angka tolak produk (reject) yang ada saat ini.

Dari Voice of Customer (VOC) PT Indokarlo Perkasa tersebut dapat ditentukan beberapa Critical to Quality (CTQ) atau dengan kata lain aspek yang paling berpengaruh terhadap kepuasan konsumen, yang dalam penelitian ini menurunnya angka persentase reject yang mencapai angka 10,34 \% pada bulan April. CTQ yang berpengaruh terhadap penurunan angka reject adalah sebagai berikut: (1) ukuran produk yang harus akurat sesuai dengan spesifikasi yang ditentukan PT IKP; (2) jenis produk yang dikirimkan kepada PT IKP harus sesuai dengan yang diminta; (3) visual produk yang dikirimkan kepada PT IKP harus dalam keadaan visual yang baik.

\section{Tahap Measure}

Setelah mendefinisikan sasaran peningkatan dan memetakan informasi kunci proses, langkah operasional kedua yang dilakukan dalam usaha peningkatan kualitas proses adalah measure atau pengukuran kinerja proses saat sekarang.

\section{Menentukan "Project Y"}

Proses memulai metode Six Sigma dengan berlandaskan rumus $Y=f(X 1, X 2, X 3, \ldots, X n)$, maka pada tahap measure ini " $Y$ " harus ditentukan terlebih dahulu agar tujuan dari penelitian ini jelas. Penentuan $Y$ dalam penelitian ini disebut dengan project $Y$, dengan kata lain project $Y$ adalah tujuan dalam penelitian yang sedang dilakukan saat ini. Project $Y$ ditentukan dari CTQ yang ada yang kemudian diprioritaskan salah satu CTQ yang akan dipilih menjadi project Y.

Berikut data yang diperoleh dari PT IKP dan diagram pareto pada bulan April 2011 mengenai banyaknya reject yang terjadi dari total populasi sebesar 1168461 unit bushing, beserta jenis rejectnya (Tabel 1).

Tabel 1

Jumlah Reject pada Bulan April Berdasarkan Jenis Reject

\begin{tabular}{lll}
\hline No & Jenis Reject & Banyak Reject \\
\hline $\mathbf{1}$ & Ukuran produk & 73063 \\
\hline $\mathbf{2}$ & Visual produk & 44798 \\
\hline $\mathbf{3}$ & Jenis Produk & 2961 \\
\hline $\mathbf{4}$ & Lain - lain & 86 \\
\hline Total & $\mathbf{1 2 0 9 0 8}$ \\
\hline
\end{tabular}

Pada data diatas dapat dilihat bahwa reject yang paling sering terjadi adalah pada jenis reject ukuran produk yang berjumlah 73063 unit (60.4\%) dari total 120908 unit yang reject pada bulan April. Berdasarkan diagram tersebut, penelitian ini akan lebih difokuskan kepada jenis reject "ukuran produk" yang bermasalah. Ukuran dari produk juga ditentukan dari banyak ketentuan, yaitu: panjang, diameter, chamfer (kemiringan), ulir (part tertentu/special cause), dan topi (part tertentu/special cause).

Suatu produk dapat dikatakan mempunyai ukuran standar dan bisa masuk dalam kategori finished good apabila semua ketentuan ukuran diatas berada di dalam batas spesifikasi. Oleh karena itu dilakukan pengambilan data ketentuan ukuran manakah yang paling sering menjadi penyumbang dari 
angka reject "ukuran produk". Berikut data yang diperoleh dari hasil penelitian lebih lanjut berserta diagram Pareto (Tabel 2).

Tabel 2

Banyaknya Reject Berdasarkan Ukuran Produk

\begin{tabular}{lll}
\hline No & Ukuran Produk & Banyak Reject \\
\hline 1 & Panjang & 29020 \\
\hline 2 & Chamfer & 21676 \\
\hline 3 & Diameter & 15512 \\
\hline 4 & Ulir & 6048 \\
\hline 5 & Topi & 807 \\
\hline \multicolumn{2}{l}{ Total } & 73063 \\
\hline
\end{tabular}

\section{Measurement System Analysis (MSA)}

Pada tahap measurement system analysis ini dilakukan pengukuran terhadap kinerja dari alat ukur yang digunakan untuk melakukan pengukuran. Untuk melakukan measurement system analysis digunakan tools yang disebut "The Gage R\&R Study", yaitu metode untuk menganalisis suatu sistem pengukuran untuk menentukan jumlah dan jenis variasi (kesalahan) yang dialami ketika mengukur sesuatu. Untuk melakukan metode ini dilakukan pengambilan data terhadap tiga orang inspector yang akan melakukan pengukuran terhadap lima part yang memiliki ukuran standar $32(3,2 \mathrm{~cm})$. Tiap part akan dilakukan pengukuran dua kali tiap inspector-nya dengan menggunakan alat ukur yang sama. Berikut di adalah data yang telah diambil (Tabel 3).

Tabel 3

Data Hasil Pengukuran Inspector

\begin{tabular}{cccccccc} 
No. & Part & Inspector & Length & No. & Part & Inspector & Length \\
\hline 1 & 1 & asep & 32.19 & 16 & 3 & suhari & 32.20 \\
\hline 2 & 1 & asep & 32.20 & 17 & 4 & suhari & 32.19 \\
\hline 3 & 2 & asep & 32.26 & 18 & 4 & suhari & 32.20 \\
\hline 4 & 2 & asep & 32.25 & 19 & 5 & suhari & 32.20 \\
\hline 5 & 3 & asep & 32.20 & 20 & 5 & suhari & 32.19 \\
\hline 6 & 3 & asep & 32.21 & 21 & 1 & adi priyogi & 32.19 \\
\hline 7 & 4 & asep & 32.20 & 22 & 1 & adi priyogi & 32.20 \\
\hline 8 & 4 & asep & 32.21 & 23 & 2 & adi priyogi & 32.25 \\
\hline 10 & 5 & asep & 32.19 & 24 & 2 & adi priyogi & 32.24 \\
\hline 11 & 1 & asep & 32.20 & 25 & 3 & adi priyogi & 32.20 \\
\hline 12 & 1 & suhari & 32.19 & 26 & 3 & adi priyogi & 32.19 \\
\hline 13 & 2 & suhari & 32.19 & 27 & 4 & adi priyogi & 32.19 \\
\hline 14 & 2 & suhari & 32.25 & 28 & 4 & adi priyogi & 32.20 \\
\hline 15 & 3 & suhari & 32.25 & 29 & 5 & adi priyogi & 32.19 \\
\hline
\end{tabular}

Sumber: pengolahan data 
Dari seluruh hasil yang didapatkan, dapat disimpulkan bahwa alat ukur, serta orang yang mengukur (inspector) dan juga cara pengukuran yang dilakukan sudah baik dan bisa diterapkan dan dilakukan untuk melakukan pengukuran terhadap part yang akan digunakan untuk penelitian ini.

\section{Data Collection Plan}

Data yang akan diambil akan digunakan untuk perhitungan lebih lanjut sampai ke bagian analyze yang akan mencari tahu penyebab dari terjadinya defect panjang, sehingga perencanaan pengambilan data ini harus direncanakan agar mengetahui data apa saja yang harus diambil dan seberapa banyak data yang diperlukan untuk melakukan perhitungan-perhitungan. Perencanaan pengambilan data juga perlu dilakukan agar data yang diambil tidak asal-asalan atau tidak memenuhi spesifikasi yang diinginkan yang mengakibatkan data harus diambil ulang dan menghabiskan banyak waktu. Perencanaan pengambilan data akan dilakukan dengan dua metode, yaitu: uji kecukupan data dan Fishbone Diagram.

Uji kecukupan data dilakukan untuk mengeyahui banyaknya sampel yang diperlukan untuk mewakili suatu karakteristik dari keseluruhan suatu populasi. Dalam penelitian ini akan digunakan rumus Slovin karena ukuran populasi yang akan diambil sampelnya diketahui jumlahnya.

di mana:

$$
\mathrm{n}=\left(\frac{N}{1+\alpha^{2} \cdot N}\right)
$$

$\mathrm{N}=$ Jumlah Populasi

$\mathrm{N}$ selama 4 hari $=4$ hari $\mathrm{x} 13 \mathrm{mesin} \times 2$ shift $\mathrm{x} 4000 \mathrm{unit} / \mathrm{mesin} / \mathrm{shift}$

$\mathrm{N}$ selama 4 hari $=416000$ unit populasi yang dihasilkan selama 4 hari.

Keterangan:

Pengambilan sampel dilakukan selama 4 hari $=4$ hari

Jumlah mesin yang digunakan untuk proses produksi $=13$ mesin

Shift yang digunakan untuk proses produksi $=2$ shift

Kapasitas produksi $=4000 \mathrm{unit} / \mathrm{mesin} / \mathrm{shift}$.

$\mathrm{n}=\left(\frac{416000}{1+(0.05)^{2} \cdot(416000)}\right)$

$\mathrm{n}=399.62=400$ sampel minimal yang harus di ambil dari bagian produksi.

Fishbone Diagram (Gambar 2) digunakan untuk mencari penyebab yang diperkirakan menjadi penyebab dari terjadinya defect panjang. Dari penyebab defect panjang tersebut bisa diperkirakan data apa saja yang akan diambil sehingga bisa digunakan untuk perhitungan selanjutnya yang mencaritahu penyebab sebenarnya dari defect panjang.

\section{Menghitung Kapabilitas Proses}

Untuk menghitung kapabilitas proses yang ada saat ini akan dimulai dengan melakukan uji normalitas. Uji ini dilakukan untuk mengetahui apakah data sampel yang diambil bisa mewakili populasi yang ada atau disebut juga normal, sehingga hasil penelitian yang dilakukan berdasarkan data sampel tersebut bisa dipercaya. Uji normalitas menggunakan data dari nilai maximum dan minimum tiap sampel yang ada. Data-data tersebut kemudian dikurangi dengan standart panjang masing-masing part baik nilai maximum maupun minimum. Hal ini dilakukan agar bisa membandingan dengan part lain walaupun panjang standart part-nya berbeda.

Pada pengukuran kapabilitas proses ini karena potong 1 dan potong 2 mempunyai toleransi ukuran yang berbeda, pengukuran kapabilitas proses potong 1 dan potong 2 pun dipisahkan, hasilnya terlihat pada Tabel 4. 


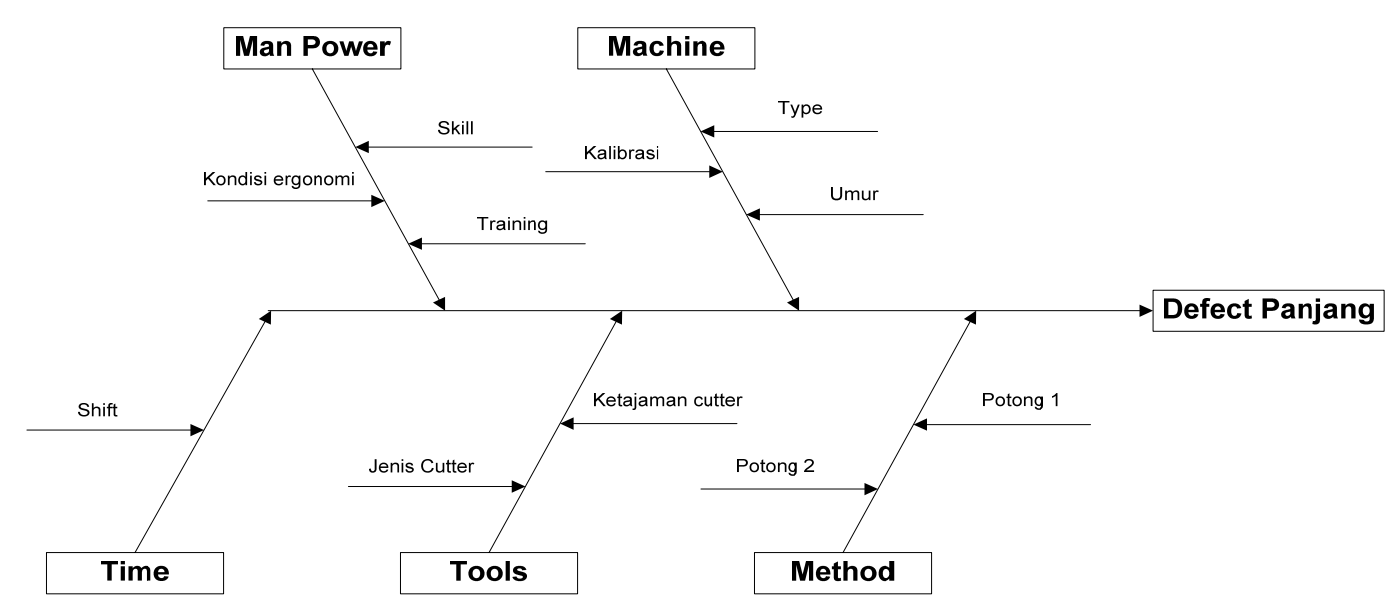

Gambar 2. Diagram Fishbone defect panjang.

Tabel 4

Hasil Ukur Potong 1 dan 2

\begin{tabular}{cll}
\hline & Potong 1 & Potong 2 \\
\hline Zst & 0.36 & 0.32 \\
\hline Zlt & 0.20 & 0.43 \\
\hline Zshift & 0.16 & 0.75 \\
\hline
\end{tabular}

\section{Tahap Analyze}

Dengan berlandaskan rumus $\mathrm{Y}=\mathrm{f}(\mathrm{X} 1, \mathrm{X} 2, \mathrm{X} 3, \ldots, \mathrm{Xn})$, pada tahap analyze ini akan dilakukan perhitungan dari data-data yang ada berdasarkan $\mathrm{X}$ (fakor-faktor yang mempengaruhi $\mathrm{Y}$ ) yang memungkinkan untuk mencari tahu faktor apakah yang paling berpengaruh terhadap $\mathrm{Y}$ (mengurangi defect panjang), sehingga pada tahap improve bisa di fokuskan terhadap X tersebut. Proses perhitungan diatas disebut juga dengan proses screening atau proses penyaringan dari beberapa $\mathrm{X}$ kemudian disaring sehingga tersaring $\mathrm{X}$ yang paling berpengaruh terhadap $\mathrm{Y}$.

Perhitungan yang akan dilakukan adalah $\mathrm{T}$ distribution dengan 2 sample $\mathrm{T}$-test melalui software Minitab. Data yang ada akan dimasukan ke dalam minitab dan kemudian dilihat apabila $\mathrm{P}$ value-nya lebih besar dari $0.05(\alpha=0.05)$, dinyatakan $\mathrm{X}$ tersebut tidak menjadi faktor penyebab dari Y. Perhitungan dilakukan dengan memisahkan dua proses yang ada antara proses potong 1 dengan proses potong 2. Adapun $\mathrm{X}$ yang memungkinkan berpengaruh terhadap $\mathrm{Y}$ adalah:

$\mathrm{X} 1=$ shift

$\mathrm{X} 2=$ machine

$\mathrm{X} 3=$ man power

$\mathrm{X} 4=$ tools

Untuk melakukan perhitungan 2 sampel T-test harus dilakukan pengambilan data berdasarkan $\mathrm{X}$ yang telah ditentukan. Data yang diambil adalah data yang mempunyai dua kondisi yang hampir sama dimana hanya $\mathrm{X}$ yang ditentukanlah yang berbeda. Berikut adalah perhitungannya. Dari data tersebut kemudian diproses di minitab dan menghasilkan nilai p-value yang bisa digunakan untuk mengambil keputusan $\mathrm{X}$ mana yang paling berpengaruh terhadap $\mathrm{Y}$ dan juga boxplot diagram yang bisa digunakan untuk membandingkan mean antar data yang pertama dengan data kedua. 
Dari Hasil perhitungan dengan 2 T-test dapat dilihat nilai p-value (Tabel 5 dan 6) yang telah didapatkan untuk mengambil keputusan faktor $\mathrm{X}$ mana yang menjadi penyebab dari defect panjang:

Tabel 5

P-value Proses Potong 1

\begin{tabular}{clcl}
\hline No & \multicolumn{1}{c}{ X } & P-value & \multicolumn{1}{c}{$\boldsymbol{\alpha}=\mathbf{0 . 0 5}$} \\
\hline 1 & Shift & 0.175 & P value $>\alpha$ \\
\hline 2 & Machine & 0.000 & P value $<\alpha$ \\
\hline 3 & Man Power & 0.929 & P value $>\alpha$ \\
\hline 4 & Tools & 0.837 & P value $>\alpha$ \\
\hline
\end{tabular}

Tabel 6

P-value Proses Potong 2

\begin{tabular}{cccc}
\hline No & $\mathbf{X}$ & P-value & $\boldsymbol{\alpha}=\mathbf{0 . 0 5}$ \\
\hline 1 & Shift & 0.574 & P value $>\alpha$ \\
\hline 2 & Machine & 0.000 & P value $<\alpha$ \\
\hline 3 & Man Power & 0.128 & P value $>\alpha$ \\
\hline 4 & Tools & 0.847 & P value $>\alpha$ \\
\hline
\end{tabular}

Dari hasil di atas dapat dilihat bahwa mesin adalah $\mathrm{X}$ yang paling berpengaruh terhadap $\mathrm{Y}$, dapat dilihat dari nilai p-value yang lebih kecil dari 0.05 . Oleh karena itu pada tahap improve akan dilakukan beberapa rencana perbaikan pada bagian mesin, yang kemudian akan dipilih perbaikan apa yang paling efektif.

\section{Tahap Improve}

Pada tahap improve ini akan dilakukan penelitian dengan metode design of experiment (DOE) yang berguna untuk mencari solusi dari mesin yang digunakan untuk produksi yang paling berpengaruh terhadap defect panjang. DOE akan memberikan solusi terbaik dari beberapa solusi yang akan dilakukan sehingga keefektifan dan efesiensi mesin akan mencapai nilai optimum dari beberapa solusi tersebut. Observasi lapangan kembali dilakukan dan setelah diperhatikan lebih lanjut putaran yang ditimbulkan mesin terhadap material pipa besi yang akan dipotong tidak stabil sehingga menjadi penyebab utama dari terjadinya defect panjang oleh mesin. Putaran material pipa besi yang tidak stabil muncul karena material yang tidak lurus atau terlalu panjang sehingga putaran menjadi tidak stabil.

Menggunakan metode DOE, tiga faktor mesin yang kami usulkan untuk diperbaiki adalah, Front Holder, Standarisasi Bandul, dan Back Holder. Setelah DOE didapatkan hasil,yaitu dengan melakukan perbaikan pada bagian mesin yang menjadi pengaruh terbesar terhadap cacat panjang maka didapatkan solusi menambah tiga tools, yaitu front holder, backholder dan juga melakukan standarisasi bandul. Dengan menambah ketiga tools tersebut diharapkan bisa mengurangi defect panjang.

\section{Tahap Control}

Setelah perbaikan yang dilakukan pada fase improve terbukti dapat mengurangi tingkat kecacatan panjang pada Bushing yang diteliti, langkah selanjutnya adalah bagaimana kemajuan yang telah dicapai dapat dipertahankan agar tidak kembali kepada kondisi semula yang lebih buruk sebelum 
dilakukan langkah improve. Agar kemajuan yang sudah tercapai tidak kembali ke tahap awal, maka diperlukan suatu standarisasi instruksi kerja, diharapkan kinerja 1 operator dan operator lainnya tidak berbeda signifikan sehingga perlu dibuatnya Standard Operating Procedure (SOP). Selain itu agar performanya tidak menurun kembali, kami mengusulkan perlu dilakukan audit 5R secara berkala yang dapat menunjang kualitas produk yang dihasilkan dapat stabil. Apabila semua solusi diterapkan dan dilaksanakan sesuai dengan SOP yang dirancang serta dicontrol dengan audit 5R, diperkirakan akan terjadi penurunan sampai dengan 87\%. Dengan value diperkirakan sebesar Rp 8,836,100.00 setiap bulannya dan apabila diterapkan terus selama setahun akan mengurangi reject sebesar Rp106,033,200.00 selama satu tahun.

\section{PENUTUP}

Berdasarkan hasil penelitian yang telah dilakukan, dapat ditarik kesimpulan sebagai berikut: (1) pada tahap define bisa dilihat proses yang ada dan dapat dari data yang ada dapat ditarik kesimpulan bahwa ukuran panjang bushing merupakan jenis defect yang paling banyak terjadi; (2) pada tahap measure juga dilakukan penentuan tujuan penelitian atau "Project $Y$ ", yaitu pengurangan defect ukuran panjang. Hasil perhitungan MSA telah membuktikan bahwa alat ukur yang digunakan untuk mengukur data dapat berjalan dengan baik dan sistem pengukuran yang dilakukan inspector juga sudah baik. Dari hasil perhitungan didapatkan kapabilitas proses yang ada saat ini masih kurang baik, karena memiliki nilai Zst atau sigma yang masih kecil, yaitu sebesar 0,36; (3) pada tahap analyze diketahui penyebab terjadinya defect panjang dan didapatkan hasil bahwa mesin yang digunakan untuk memotong adalah faktor yang paling berpengaruh terhadap terjadinya defect panjang yang jumlahnya cukup banyak; (4) pada tahap improve dilakukan penelitian dengan melakukan improvement pada bagian mesin yang menjadi pengaruh terbesar terhadap cacat panjang dan didapatkan solusi menambah tiga tools, yaitu front holder, backholder dan juga melakukan standarisasi bandul; (5) pada tahap control form SOP dan 5R di rancang guna mendukung tools yang akan ditambahkan ke mesin. Dan apabila tools tambahan dipasang ke mesin dan dijalankan sesuai dengan prosedur yang telah dirancang, maka defect panjang diperkirakan akan berkurang sampai dengan $87 \%$, dengan value yang bisa didapatkan sekitar Rp8,836,100.00 setiap bulannya dan apabila dijalankan selama setahun bisa mendapatkan value sebesar Rp106,033,200.00.

Dari hasil temuan, berikut adalah beberapa hal yang disarankan untuk peningkatan kualitas di perusahaan: 91) ukuran panjang bushing harus lebih diperhatikan kualitasnya; (2) Zst yang pada keadaan semula berada di bawah standar, perlu dilakukan tindakan perbaikan untuk meningkatkan Zst; (3) setelah diketahui faktor mesinlah yang paling berkontribusi besar atas besarnya jumlah produk defect, sebaiknya dilakukan tindakan perbaikan di faktor yang berkaitan dengan mesinnya; (4) tambahkan front holder, backholder dan juga melakukan standarisasi bandul pada mesin untuk mengurangi jumlah produk defectyang dihasilkan; (5) jalankan SOP yang dibuat dan lakukan audit 5R secara rutin agar kondisi yang sudah membaik tidak kembali ke kondisi semula.

\section{DAFTAR PUSTAKA}

Desai, T. N. \& Shrivastava, D. R. (2008). Six Sigma: Sebuah arah baru kualitas dan produktivitas manajemen. Prosiding Kongres Dunia tentang Teknik dan Ilmu Komputer, 2.

Donald, L., Suzanne, B., \& Elaine, C. (2003). How to scope DMAIC projects. Quality Progress, 36 $(1), 37-41$. 
Dreachslin, J. L. (2007). Applying Six Sigma and DMAIC to diversity Initiatives. Journal of Health care Management, $361-367$.

Evans, J. R., \& Lindsay, W. M. (2007). An Introduction to Six Sigma \& Process Improvement. Jakarta: Salemba Empat.

Gaspersz, V. (2002). Pedoman Implementasi Program Six Sigma Terintegrasi Dengan ISO 9001: 2000, MBNQA, dan HACCP. Jakarta: Gramedia Pustaka Utama.

Gasperz, V. (2005). Total Quality Management. Jakarta: Gramedia Pustaka Utama.

Mehrjerdi, Y. Z. (2011). Six Sigma: Methodology, tools and its future. Assembly Automation, 31 (1), $79-88$.

Wijaya, L. T., \& Kusuma, N. (2008). Penerapan Metode Six Sigma untuk Meningkatkan Kualitas Hasil Produksi Kapsul Lunak Yodiol. Skripsi tidak diterbitkan. Universitas Brawijaya Fakultas Teknik, Malang. 